\title{
EDUCATING FOR FUTURE JOBS
}

\author{
Joanna Lizut \\ Janusz Korczak Pedagogical University in Warsaw, Poland \\ Gilberto Marzano \\ Rezekne Academy of Technologies, Latvia \\ Miroslaw Grewinski \\ Janusz Korczak Pedagogical University in Warsaw, Poland
}

\begin{abstract}
In a relatively short time, information and communication technology (ICT) has spread worldwide, from defense to space to large industrial applications, and to the commercial, healthcare, entertainment, and educational sectors. As a consequence, experts argue that it is urgent and critical to prepare educational programs in order to re-train the current workforce. However, there are some key questions that are very relevant, since they concern crucial and challenging issues: 1) Which jobs have a future in the digital era? 2) How can education support the acquisition of new skills required by the new jobs?

This article focuses on the above questions, and presents the main opportunities that the digital revolution offers for sustaining education for future jobs in a lifelong perspective.
\end{abstract}

Keywords: digital technology, education challenge, future jobs, labor market changes.

\section{Introduction}

It has been estimated that 47 percent of US jobs, 57 percent of jobs across the OECD, and 77 percent of jobs in China are susceptible to automation over the forthcoming decades, a substantial proportion of which are concentrated in the service sector (Frey \& Osborne, 2017).

As a consequence, many current professions and jobs will undergo changes and new ones will arise. For example, smartphones and the internet are mainly used today for social purposes, but it is expected that in the near future they will be used for increasing the productivity of workers, and that they will create new job opportunities (Leonardi, 2015; Kwahk \& Park, 2016; van Zoonen, Verhoeven, \& Vliegenthart, 2016).

However, although many manual works will be automated, it is undoubtedly true that professions such as barber, janitor, farm worker, house cleaner, cook, gardener, repairman, carpenter, caregiver, etc., will remain largely stable, since these jobs require complex manual abilities as well as specific intellectual skills. 
Nowadays, the category of complex manual jobs employs about 19 percent of workers in OECD states, and it is considered likely that the figure will remain at roughly this level (Halal et al., 2016).

A recent report by the World Bank (2016) argues that the number of jobs directly created by digital technologies is fairly modest, but the number of jobs enabled by them can be significant, as the 10 million jobs created in online stores in China by the country's booming e-commerce demonstrates (World Bank, 2016). The same report underlines that the lives of the majority of the world's population will remain largely untouched by the digital revolution. In fact, data shows that only around 15 percent of the world's population can afford access to broadband internet, meaning that, at least in the short term, advanced internet services will remain unavailable, inaccessible, and unaffordable to the majority (Figure 1).

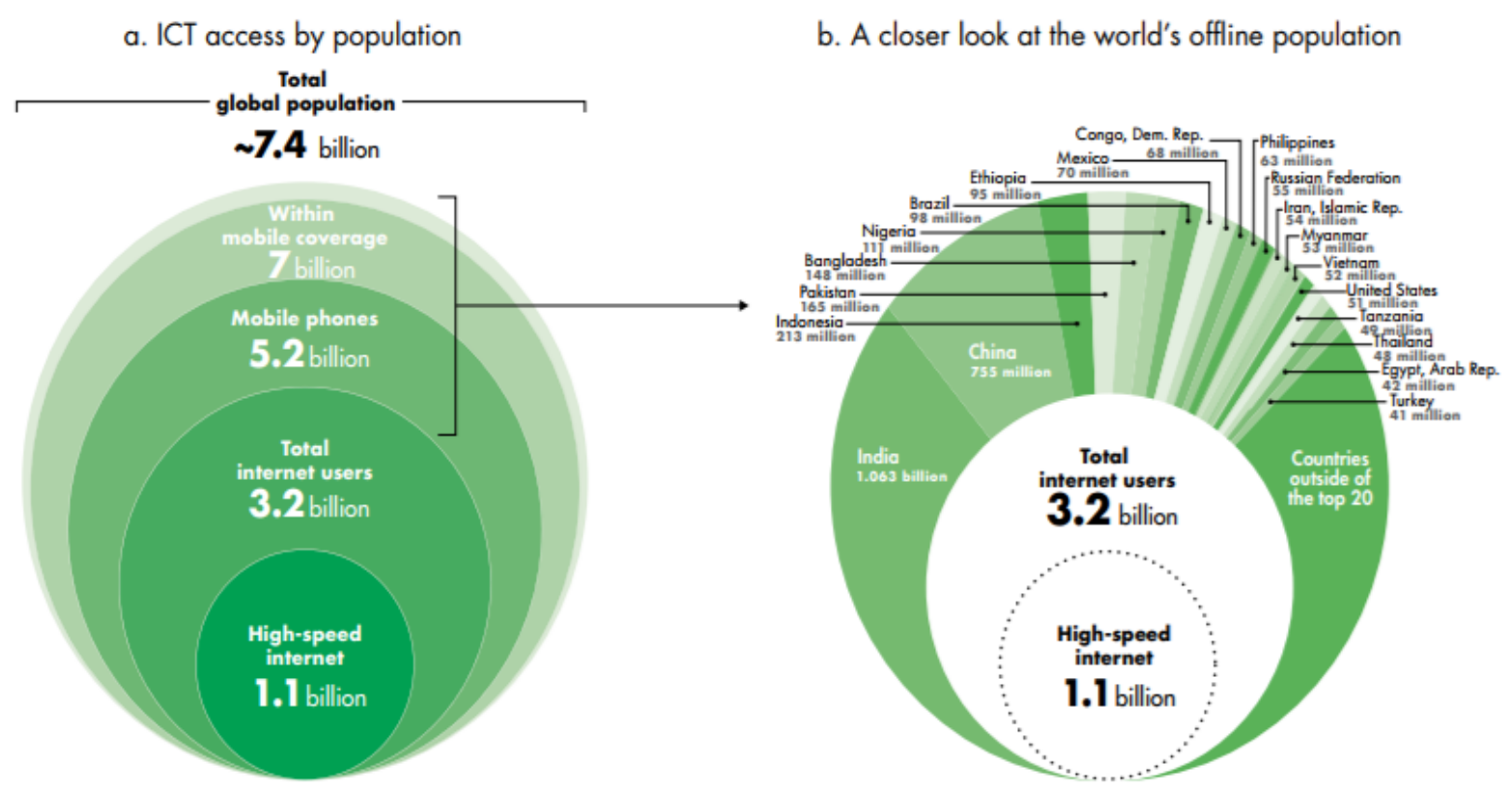

Figure 1. Internet access by world population (source: World Bank, 2016: 8)

As a consequence, we can expect that in developing countries the impact of digital technology does not appear to be immediate, but in the next few decades the effects of the digital divide, both physical and cultural, could be really disastrous, and will only serve to reinforce existing inequalities. In fact, the digital divide will prevent access to essential services, media, and information that will be ever more sophisticated and require broadband connection as well as digital skills.

There is broad consensus that education will play a crucial role in minimizing the negative impacts of the spread of digital technology. This article focuses on the challenges and opportunities that the digital revolution offers for sustaining 
education for future jobs in a lifelong perspective. It results from an ongoing research being conducted into the labor market of the future.

\section{Research methodology}

The research was based on a systematic analysis of the literature conducted by the authors. Following the general guidelines of the systematic literature review method (Moher et al., 2009), we analyzed the current literature available on databases such as SAGE, the Institute for Employment Research, World Development Indicators, and NBER Working Papers, as well as reports published by international organizations (Eurostat, World Bank, OECD, and so on). The process of identifying and reviewing the literature was conducted in two phases in 2017. In the first phase, from January-June 2017, we searched for combinations of keywords, such as 'future professions', 'future jobs, 'new skills', 'labor market', 'technology impacts', 'labor world changes', and 'workers' challenges'. We collected a total of 245 articles and 32 reports. A screening was then made based on abstracts. We decided to eliminate material published before 2013. We also used Google scholar to evaluate the popularity of articles, taking account of their citations. At the end of the screening process, 87 articles and 11 reports were selected. In the second phase (July-December 2017), selected materials were classified according to four main themes:

- $\quad$ Future changes in the labor market (22 articles, 5 reports)

- $\quad$ Future of skills and competencies (41 articles, 8 reports)

- $\quad$ Future of Professions and Jobs (33 articles, 9 reports)

- Challenges for the educational system and Lifelong Learning (19 articles, 3 reports)

Some articles and reports were assigned to more than one class, on account of their overlapping content. The selected materials were then analyzed by the authors, and a preliminary report was drawn up. This will be discussed at an international meeting in order to define a new research project.

This article synthesizes the findings that emerged from our research on future skills and educational needs.

\section{Educational issues}

Experts and professionals are persuaded that investments in lifelong learning by government, industry, and professional bodies can mitigate the negative effects of technology on the labor market. Modular educational programs should be created which are constantly updated in response to changing skill demands.

From our research, the principal educational questions related to changes in the labor market can be summarized as follows: 
- What are the most important skills needed to succeed in the workforce of the future?

- Which of these skills can be taught effectively via online systems through a self-learning and social learning approach?

- Which skills present teaching challenges?

- What new types of credentialing systems should support non-formal and informal learning programs?

- How can traditional educational models be improved through digital technologies?

Figure 2 presents the skills for the future, many of which involve digital competencies and innovative attitudes.

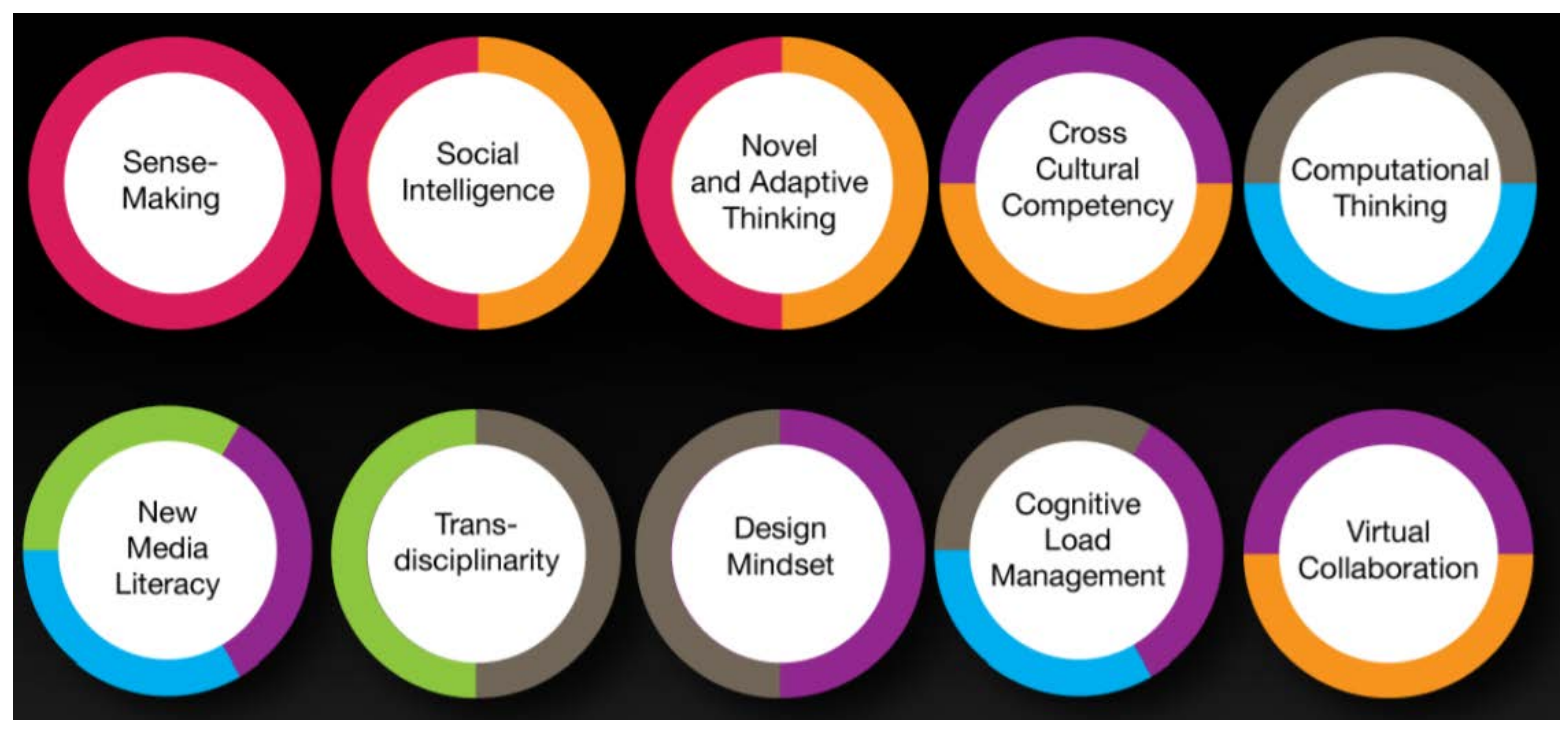

Figure 2. Ten skills for the future (source: Tracey Wilen-Daugenti) ${ }^{1}$

Experts unanimously indicate that critical thinking and creative thinking are crucial factors for the success of the future workforce.

Nevertheless, current data on the composition of the labor market seems to contradict the experts' opinion, at least in the short term. At present, workers who are really creative and innovative often encounter various difficulties to be hired, since they are considered to be problematic to manage and, therefore, less reliable. Indeed, many organizations discourage leaders from being strategic and thinking beyond what the organization is currently doing, since greater rewards are harvested by simply doing what has always been done well. In this regard, what Perry, the popular executive recruiter, observed in 2009 remains valid:

\footnotetext{
${ }^{1}$ Careers 3.0 Future Skills Future Work, slide presentation; available at https://www.oecd.org/site/eduimhe12/Tracey\%20Wilen-Daugenti.pdf; last accessed on 10.11.2017.
} 
Let me emphasize that creativity is not appreciated by most HR people. HR - and rightfully so - are the last bastion of risk avoidance in a company. Thinking outside the box doesn't apply. They want you in the box. ${ }^{2}$

Furthermore, there are also some managers who restrain innovative initiatives that they don't understand whilst, in many public institutions, ineffective information systems that don't meet the emerging needs and societal changes complicate the life of workers who are creative and critical thinking.

From our research, it emerges that acquiring skills in computational thinking could be more fruitful for promoting novel attitudes to thinking. Computational thinking is a method of thought that is used in computer sciences (Grover \& Pea, 2013), but experts argue that it can also influence the way people solve any type of problem.

Computational thinking can be understood as the mental activity of formulating a problem in such a way as to admit a computational solution (Wing, 2014).

In this regard, learning coding may help to improve the way in which any kind of problem is tackled in an increasingly digitalized world.

In the near future, computational thinking could provide the skills necessary in the sphere of work, but will also bring great social benefits since it can favor the design of innovative solutions for people's livability. Computational thinking enables complex problems to be tackled in efficient ways, as well as provide for the upscaling of good solutions.

\section{Shifting people into new professions and jobs}

There is a broad consensus that the digital revolution is moving towards the reshaping of traditional professions and jobs. Experts encourage people, especially the young, to focus on skills that they want to acquire because, whilst obtaining a professional degree, for example as an architect or engineer, is clearly important, skills are the essential prerequisite to finding and maintaining a job.

In this regard, it is demonstrative that an emerging profession is that of coach in all its multifarious variations, such as personal coach, professional coach, career coach, executive coach, etc. Indeed, coaching is a process that aims at improving individual or organizational performance, empower leadership capability, and support professionals to meet their professional and personal goals (McNally \& Lukens, R., 2006).

At the moment, to deal with the impact of digital technology on current jobs and professions, experts suggest paying attention to digital technology that will open new opportunities.

\footnotetext{
${ }^{2}$ https://www.theglobeandmail.com/report-on-business/strategies-for-the-job-hunt/article1200249/; last accessed on 22.11.2017.
} 
Moreover, online learning is considered to be a crucial means by which to sustain the skilling and re-skilling of workers. Researchers and experts argue that online learning not only reduces costs and improves access but also offers the possibility of increasing the quality of the teaching/learning experience and of the evaluation of learning achievements. Accordingly, investments in online learning are hoped for, since this would create new professional skills and facilitate the transformation of current learning programs. However, experience seems to demonstrate that the human guidance in educational processes cannot be eliminated.

We found a lot of evidence pointing to the fact that new educational skills should be created to involve learners in a collaborative online environment.

\section{Self-directed digital learning}

Companies are looking for workers who professionalize themselves in order to meet the changes brought about by advances in technology. Lifelong learning is fast becoming a must for workers and a crucial requirement for their career development.

Although topical, Self-Directed-Learning (SDL) is not a new concept. Indeed, the most commonly followed definition of SDL, coming from Knowles (1975), is as a process in which individuals take responsibility for their own learning by taking the initiative in diagnosing their own learning needs, "formulating learning goals, identifying human and material resources needed for learning, choosing and implementing appropriate learning styles and evaluating the learning outcomes" (Knowles, 1975: pg. 18).

Nowadays, SDL is often put in relation to 'cooperative learning', 'collaborative learning', and social learning, which are included in the broad area of non-formal learning and sometimes of informal learning. Web based social learning is also spreading as a consequence of the application of the social network paradigm to educational processes (McIntosh, 2016).

The advent of the Internet has increased the interest of researchers and teachers in self-directed learning due to the massive amount of knowledge and support available online. However, the effectiveness of self-directed learning depends as much on the availability of effective and controlled knowledge sources as on the attitude of learners.

From our research, the success of self-directed digital learning appears to be significantly conditioned, at least in the early stages, by the guidance of trainers in the use of technology-enhanced materials for learning (Murphy et al., 2014). To use self-directed digital learning environments, learners should be taught 
carefully. They have to know what it means to manage their own learning, and how to utilize the resources available online.

Furthermore, research is needed to understand the role of non-cognitive learners' attitudes in self-directed online learning environments, for example in relation to motivation, persistence, and resourcefulness.

We are persuaded that in the short term, and especially in the case of adult education, hybrid solutions should be preferred that integrate self-online learning with online collaborative guidance.

\section{Training ecosystem}

Nowadays, one of the main challenges in education and training is the definition of effective learning programs in a lifelong learning perspective. Indeed, as our research has shown, people's employability depends on various skills, such as their capacity for team-work, advanced communication, critical thinking, and problem-solving. We also found that great emphasis is put on interactive teaching and on practices that can reinforce learner's reflections and experience-based exercises.

Many authors highlight that an interactive teaching approach requires skilled trainers and well-designed programs. In this regard, we have to underline that an increasing number of educators have to deal with digital technologies that, recently, have come to include ubiquitous computing and cloud computing applications. The Internet, today, appears as a massive repository where precious information is buried under a huge mass of useless and rubbish data. As a consequence, new paradigms and tools, as well as new skills, are needed to find and handle big volumes of data available on the internet. It is possible to highlight some emerging professions in the field of Information Technology.

- Machine learning specialist. The demand for cognitive computing skills is gaining attention. Candidates should be skilled in unstructured data processing, statistical extraction of entities, machine learning, natural language processing, and online searching. Requirements are for a degree in Machine Learning, Statistics, Applied Mathematics, Computer Science, Information Systems, or a related quantitative discipline, with a minimum of five years of relevant experience.

- Blockchain engineer. A blockchain engineer is a person who is responsible for everything relating to Bitcoin in a company, and who designs procedures in order to accept and process Bitcoin transactions. They must be expert in cryptography, distributed systems, and hash algorithms, as well as in trading platform and secure identification. 
- Virtual reality engineer. Virtual reality is not a prerogative of game applications. A virtual reality engineer is an expert in the definition and execution of advanced technologies for Virtual Reality.

- $\quad$ IoT architect. An IoT architect's job consists of designing end-to-end IoT solutions that solve real business problems in many fields (for example, in the automotive, aerospace, and medical equipment industries, and in manufacturing, electronics, telecommunications, etc.). The IoT architect position combines domain knowledge, technical skills, and the necessary competence to integrate various disciplines.

- Cybersecurity specialist. A cybersecurity specialist analyzes alerts from multiple and various sources within both public and private organizations in order to determine possible causes of such alerts, identifying and distinguishing between false and real cybersecurity incidents. Indeed, a cybersecurity issue takes places any adversary seeks to gain something from their activity, for example obtaining private information, undermining the system, or preventing its legitimate use (Singer \& Friedman, 2014).

Finally, it is expected that IoT will spread to education, allowing the construction of intelligent instructional environments, to enrich experimental teaching, to assist educational management, and to extend educational activities outside the classroom (Harmon, Castro-Leon, \& Bhide, 2015).

\section{Conclusion}

In their study, Frey and Osborn observed that engineering and science-based occupations have a low susceptibility to computerization. They argue that this is largely due to the high degree of creative intelligence that engineering and scientific tasks require.

Although the literature abounds with appreciation for innovation and creativity, organizations, especially large ones, stifle creativity with rules and provide no slack for innovation. The reasons for this are well be synthesized by Serrat:

Monopolistic structures, "adhocism," tight budgets, and heavy workloads can also hinder the long-term investment and commitment that is needed to truly embed a culture of innovation. Paradoxically, the need to keep up sometimes also means that new technologies or ways of working are adopted before a prior innovation takes root (Serrat, 2017: 907).

The deficit in innovation will create serious problems for workers and citizens, since it will either disincentive the reskilling of workers, or increase the bureaucratic burden for citizens due to the computerization of procedures that have not been rethought appropriately. 
Experts suggest investing in education to exploit the opportunities offered by the technological revolution. However, ongoing transformations will not wait for the reform of the current educational system. It is therefore urgent and critical to prepare educational programs in order to re-train the current workforce. In this regard, governments should develop effective policies to sustain the educational effort and favor innovation, especially social innovation, and make people aware of the challenges that await them.

\section{References}

Frey, C. B., \& Osborne, M. A. (2017). The future of employment: how susceptible are jobs to computerisation? Technological Forecasting and Social Change, 114, 254-280.

Grover, S., \& Pea, R. (2013). Computational thinking in K-12: A review of the state of the field. Educational Researcher, 42 (1), pp. 38-43. Available at: http://lifeslc.org/docs/LSLC_rp_A189_Grover-Pea_ER_K-12CT.pdf; last accessed on 19.01.2018.

Halal, W., Kolber, J., Davies, O., \& Global, T. (2016). Forecasts of AI and Future Jobs in 2030: Muddling Through Likely, with Two Alternative Scenarios. Journal of Futures Studies, 21 (2), 83-96.

Harmon, R. R., Castro-Leon, E. G., \& Bhide, S. (2015, August). Smart cities and the Internet of Things. In Management of Engineering and Technology (PICMET), 2015 Portland International Conference on, 485-494).

Knowles, M. (1975). Self-directed learning: a guide for learners and teachers. Follett.

Kwahk, K. Y., \& Park, D. H. (2016). The effects of network sharing on knowledge-sharing activities and job performance in enterprise social media environments. Computers in Human Behavior, 55, 826-839.

Leonardi, P. M. (2015). Ambient Awareness and Knowledge Acquisition: Using Social Media to Learn" Who Knows What" and" Who Knows Whom". Mis Quarterly, 39 (4), 747-762.

McIntosh, D. (2014). Vendors of learning management and e-learning products. Learning Management Vendors, 2014, 88-96.

McNally, K., \& Lukens, R. (2006). Leadership development: An external-internal coaching partnership. Journal of Nursing Administration, 36 (3), 155-161.

Moher, D., Liberati, A., Tetzlaff, J., Altman, D. G., \& The PRISMA Group (2009). Preferred Reporting Items for Systematic Reviews and Meta-Analyses: The PRISMA Statement, PLoS Med. 6 (7). Available at: http://journals.plos.org/plosmedicine/article?id= 10.1371/journal.pmed.1000097; last accessed 19.01.2018.

Murphy, R., Snow, E., Mislevy, J., Gallagher, L., Krumm, A., \& Wei, X. (2014). Blended learning report. Michael \& Susan Dell Foundation. Available at: https://www.edweek. org/media/msdf-blended-learning-report-may-2014.pdf; last accessed 19.01.2018.

Serrat, O. (2017). Knowledge Solutions: Tools, Methods, and Approaches to Drive Organizational Performance, Springer.

Singer, P. W., \& Friedman, A. (2014). Cybersecurity: What Everyone Needs to Know. Oxford University Press.

van Zoonen, W., Verhoeven, J. W., \& Vliegenthart, R. (2016). How employees use Twitter to talk about work: A typology of work-related tweets. Computers in Human Behavior, 55, 329-339. 
Wing, J. (2014). Computational thinking benefits society. 40th Anniversary Blog of Social Issues in Computing, 2014. Available at: http://www.utad.pt/vPT/Area2/eventos/ Documents/Artigo\%203.pdf; last accessed on 19.01.2018.

World Bank (2016). Digital Dividends. World Development Report 2016, The World bank. 